\title{
Scleractinian corals as facilitators for other invertebrates on a Caribbean reef
}

\author{
J. A. Idjadi ${ }^{1, *}$, P. J. Edmunds ${ }^{2}$ \\ ${ }^{1}$ Department of Biology, University of Delaware, Newark, Delaware 09702, USA \\ ${ }^{2}$ Department of Biology, California State University, 18111 Nordhoff Street, Northridge, California 91330-8303, USA
}

\begin{abstract}
There is increasing evidence that facilitative effects of various organisms can play important roles in community organization. However, on tropical coral reefs, where scleractinian corals have long been recognized as important foundation species creating habitat and resources that are utilized by a diversity of taxa, such relationships have rarely been studied and never within the contemporary theoretical context of facilitation. In the present study, we surveyed coral reefs on the south coast of St. John, US Virgin Islands, with the goal of quantifying the relationship between 'coral traits' (3 distinctive characteristics of scleractinian communities) and the abundance and diversity of benthic invertebrates associated with the reefs. We defined coral traits as coral diversity, percentage cover of live coral, and the topographic complexity created by coral skeletons, and statistically evaluated their roles in accounting for the abundance and diversity of conspicuous invertebrates at 25 sites. The analysis yielded contrasting results in terms of the putative facilitative roles of scleractinian corals. Coral traits were significantly and positively related to the diversity of reef-associated invertebrates, but were not related to invertebrate abundance. Topographic complexity (but not coral cover) had relatively strong explanatory ability in accounting for the variation in invertebrate diversity, although a substantial fraction of the variance in invertebrate diversity $(45 \%)$ remained unexplained. While these results are correlative, they demonstrate that a statistical majority of the variation in the diversity of conspicuous invertebrates on Caribbean reefs can be explained by the role of coral skeletons in creating topographic relief with diverse morphologies, although processes independent of coral traits also play important roles. In an era of globally declining coral cover, these findings suggest that the progressive loss of coral skeletons from tropical reefs will lead to substantial losses of invertebrate diversity that might initially be obscured by conserved abundances.
\end{abstract}

KEY WORDS: Coral · Scleractinian · Facilitation · Invertebrates · Caribbean - Resale or republication not permitted without written consent of the publisher

\section{INTRODUCTION}

Understanding the role of interspecific interactions in community organization has been a major objective of ecology for more than a century (Real \& Brown 1991). During this time, the prevailing view has considered groups of organisms as conceptual communities that operate within a broader ecological framework dominated by the consequences of negative interactions (Gleason 1926). Despite longstanding acceptance of this interpretation of community organization (Connell 1961, Real \& Brown 1991), support for an alternative view, that positive interactions are also important in community organization, has gained momentum since their incorporation into the 'keystone' and 'foundation' species concepts of Paine (1966) and Dayton (1971). Analyses of positive species interactions are now playing a significant role in contemporary studies of community structure, where their effects are described as facilitation (Bruno et al. 2003).

Plant communities have provided tractable model systems for the study of facilitation (Callaway 1998), and have demonstrated that facilitative interactions are usually species-specific yet interdependent (Call- 
away 1998). In terrestrial biomes, plant facilitators typically ameliorate environmental stress by maintaining favorable soil-water conditions, aiding seed retention, buffering temperature extremes, and providing protection from herbivores (Bertness \& Hacker 1994, Bruno \& Bertness 2000). The proliferation of reports describing facilitation (e.g., Bronstein 1994, Callaway 1998, Bruno \& Bertness 2000, Bruno et al. 2003) suggests that positive interactions have more pervasive effects on community structure than was previously thought (Bruno et al. 2003). Tropical coral reefs provide an example of a large-scale community that is probably strongly affected by facilitation created through the actions of their principle architects scleractinian corals. While some work has been done on coral-associated invertebrates (e.g. Vytopil \& Willis 2001), to date such facilitative effects have not been studied explicitly.

Tropical reef corals fulfill the functional roles of facilitators (Bruno et al. 2003) in several ways, but potentially their greatest effects are through the construction of complex skeletons that render them autogenic ecosystem engineers (sensu Jones et al. 1997). Additionally, reef corals probably support a diversity of subtle facilitative mechanisms including, for example, the supply of carbon to the reef community (Wild et al. 2004) and the creation of a complex internal milieu within which a diverse assemblage of symbiotic dinoflagellate can exist (LaJeunesse et al. 2003). Corals as ecosystem engineers (sensu Jones et al. 1997) are analogous to trees by generating physical habitats that are exploited by sessile organisms for settlement surfaces and by motile organisms for shelter (Steele 1999). Coral skeletons also form reef-scale roughness elements that modify boundary layers and create turbulent flow that enhances nutrient and zooplankton availability to the reef community (Atkinson \& Bilger 1992) and promote mass transfer to sessile taxa (Lesser et al. 1994, Shashar et al. 1996). The success of artificial reefs (i.e. 3-dimensional structures used for reef restoration) in increasing diversity and abundance of reef-associated taxa (Clark \& Edwards 1994) has underscored the important roles played by coral in providing habitat or, in other words, functioning as facilitators.

It has long been recognized that symbiotic scleractinians provide carbon to reef communities (Benson \& Muscatine 1974, Richman et al. 1975, Kayanne et al. 1995, Wild et al. 2004) and that the carbon released by corals can benefit other taxa as a food source (Coffroth 1984). However, the pathways for these effects are not well understood. Particulate coral mucus contains large quantities of carbon and nitrogen relative to other food sources in the adjacent seawater (Meikle et al. 1988) and, together with dissolved organic material
(DOM) from the coral, can provide a valuable nutritional resource for other organisms (Coffroth 1984). Presumably, mucus and DOM from corals enter the food web through direct consumption by deposit- and suspension-feeding organisms (Richman et al. 1975, Stachowicz \& Hay 1999), or after microbial enrichment (Benson \& Muscatine 1974, Wild et al. 2004) or microbial degradation within the reefal interstices (Richman et al. 1975, Wild et al. 2004). It can be expected that the relative importance of these pathways will vary with the magnitude of carbon production and release by reef corals. On coral reefs with large amounts of coral cover capable of producing mucus, especially in shallow water where corals typically produce excess carbon through photoautotrophy (Muscatine et al. 1984), the community-level consequences of organics released by corals might be large.

In the light of the potential role of scleractinians as facilitators, the increases in coral mortality (Connell 1997, Aronson \& Precht 2001, Hughes et al. 2003) have important consequences for the taxa normally associated with 'healthy' reef corals. Nevertheless, despite decades of studying the biology of reef corals and the ecology of declining coral reef health, there is a history of neglect when it comes to the less conspicuous reef invertebrates (Glasby \& Connell 2001, Dulvy et al. 2002). Apart from a few events that have led to catastrophic coral losses, such as outbreaks of the corallivorous seastar Acanthaster planci in the Pacific (Moran 1986) and severe tropical storms (Rogers 1993), little quantitative information is available concerning the consequences of coral loss for other taxa. An exception is provided by studies of the macroalgae that have replaced scleractinian corals on many reefs (McCook 1999), although such studies typically do not consider the possibility that some algae decline in abundance and/or diversity as coral cover is lost. For instance, 2 functional groups of algae that are likely to suffer in the phase changes initiated by coral death are the diverse zooxanthellae found within symbiotic corals (LaJeunesse 2002), and the crustose coralline algae that stimulate coral settlement (Morse et al. 1994, Heyward \& Negri 1999) but are out-competed by macroalgae (McClanahan et al. 2003).

The goal of this study was to explore the association between scleractinian corals and reef invertebrates in the context of potential facilitative mechanisms created by the corals. To achieve our goal, the shallow reefs of St. John, US Virgin Islands, were surveyed for traits associated with coral cover and reef invertebrates in order to quantify the relationship (if any) between the two. We restricted our analyses to shallow coral reefs (6 to $13 \mathrm{~m}$ depth), and censused only macroscopic invertebrates that could be quantified without manipulating the substratum. This approach excludes 
small and/or cryptic taxa, a restriction made necessary by limitations on collecting and sampling within a National Park (Rogers \& Beets 2001), but it has the advantage of providing the time necessary to survey multiple sites. Because we did not examine a larger size range of invertebrates or survey all niches (e.g. infauna) we could not distinguish between the following 2 effects this may have had on our results: either (1) they could swamp an association between corals and other taxa (i.e. invertebrate diversity is high regardless of coral cover), or (2) they could accentuate the association (i.e. the diversity of conspicuous and cryptic invertebrates is strongly related to coral cover). To test for an association between corals and conspicuous invertebrates, we used multiple regression techniques to quantify the extent to which coral traits (independent variables) accounted for variation in invertebrate traits (dependent variables). Our results provide support for the role of reef corals as facilitators in shallow tropical habitats, but surprisingly reef corals and the traits they are associated with, are related positively with the diversity of invertebrates but not their abundance. In the light of the statistical evidence showing that a substantial fraction of the variation in invertebrate traits was 'explained' by the coral traits, we critically evaluated facilitation as a potential mechanism driving the relationship. While manipulative experiments are necessary to explore the cause-and-effect relationships implied by our findings, such analyses will require manipulative experiments of a magnitude that would be challenging within the present-day framework of worldwide reef-degradation (Gardener et al. 2003, Hughes et al. 2003).

\section{MATERIALS AND METHODS}

A mensurative approach was used to characterize coral and invertebrate communities along $2 \mathrm{~km}$ of the south coast of St. John, US Virgin Islands (Fig. 1). The
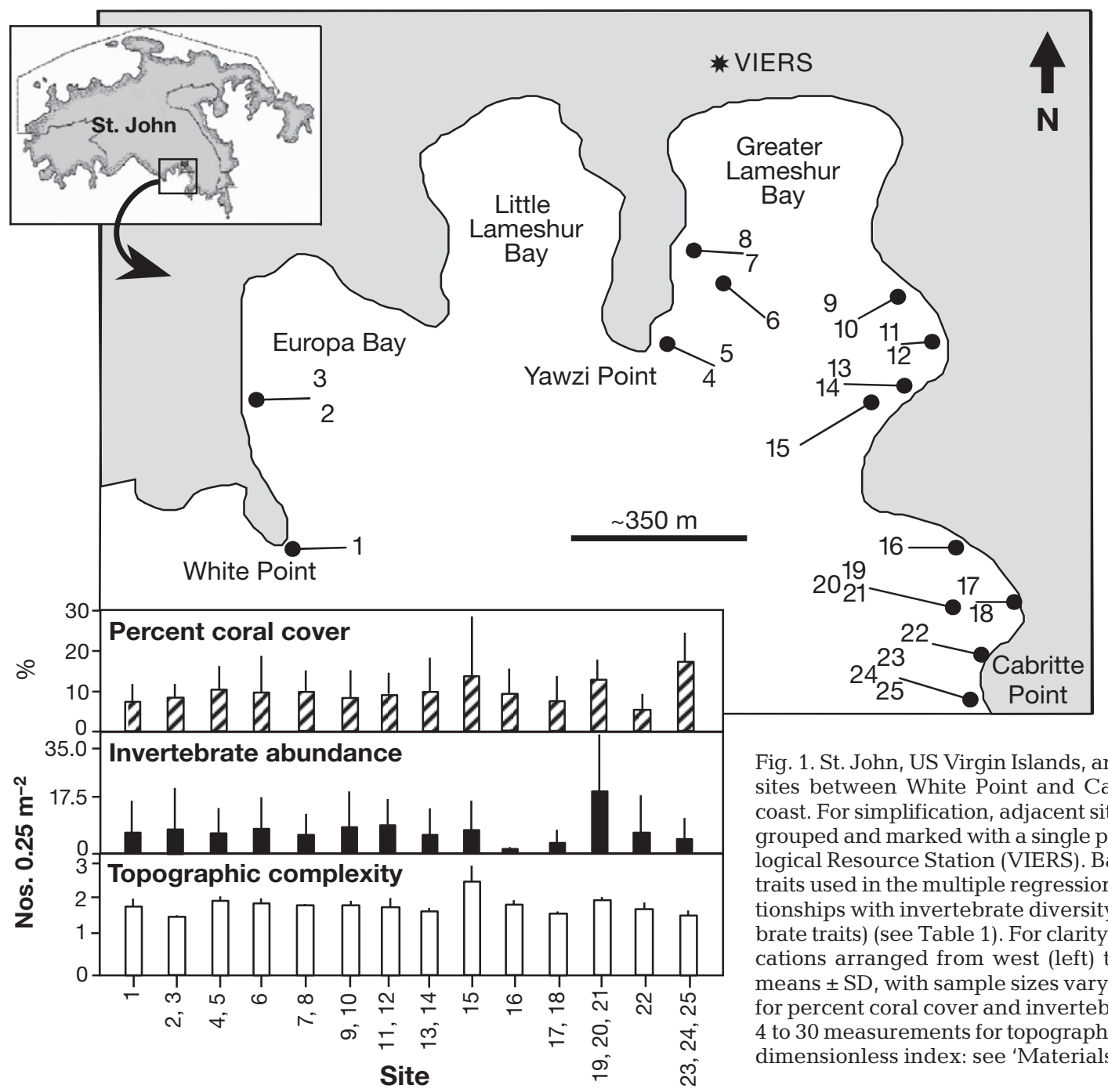

Fig. 1. St. John, US Virgin Islands, and locations of the 25 study sites between White Point and Cabritte Horn on the south coast. For simplification, adjacent sites on similar substrata are grouped and marked with a single point. *: Virgin Islands Ecological Resource Station (VIERS). Bar graphs show 2 of 3 coral traits used in the multiple regressions designed to test for relationships with invertebrate diversity and abundance (invertebrate traits) (see Table 1). For clarity, traits are displayed for locations arranged from west (left) to east (right). Values are means $\pm \mathrm{SD}$, with sample sizes varying from 10 to 30 quadrats for percent coral cover and invertebrate abundance, and from 4 to 30 measurements for topographic complexity (= rugosity, a dimensionless index: see 'Materials and methods' for details) 
Virgin Islands Environmental Resource Station (VIERS) in Great Lameshur Bay served as a base for this work. In shallow waters in this location, the reefs are predominantly fringing communities on a granite substratum (Edmunds 2002). Preliminary surveys were used to select 25 study sites between White Point and Cabritte Horn to provide a gradient of coral cover and topographic complexity on reefs 6 to $13 \mathrm{~m}$ in depth. The study sites are surrounded by a protected watershed within the Virgin Islands National Park and Biosphere Reserve (Rogers \& Beets 2001) and, apart from the tips of the headlands, are sheltered from the prevailing swells. The community structure of these reefs has been described extensively by Edmunds \& Witman (1991), Rogers et al. (1997) and Edmunds (2002).

Each study site was treated as a statistical replicate in the tests of association between corals and invertebrates, and quadrats were used to characterize each site. We surveyed 13 sites in the summer of 1999, and 12 in the summer of 2000, and each was sampled for coral and invertebrate traits using 10 quadrats $(0.5 \times$ $0.5 \mathrm{~m}$ ) placed randomly along a $30 \mathrm{~m}$ transect along the depth contour at 6 to $13 \mathrm{~m}$ depth (depending on site). Although it would have been preferable to sample all 25 sites in a single year, this proved impossible given the time required for each survey and the length of the field trips. To gain insight into the possibility that our results were biased by temporal changes in community structure, we used photographic surveys of adjacent reefs that are part of our long-term monitoring efforts (Edmunds 2002) to test for differences in community structure in 2000 compared to 1999 (see following subsections).

Quantifying coral community. The coral-community structure was characterized directly by the number of colonies and the percentage cover, and indirectly by the rugosity of the reef. Coral colonies were defined as a contiguous area of living tissue (sensu Connell 1973), and were counted after brushing aside algae and sediment as necessary to improve visibility (but without disturbing the underlying substratum). The abundance of coral colonies by species (nos. $0.25 \mathrm{~m}^{-2}$ ) and the number of coral species was used to calculate Fisher's alpha estimates of coral richness (Fisher et al. 1943). This formula provides an alpha value $(\alpha)$ which corresponds to a standard curve for each set of sampled number of individuals $(N)$ and observed number of species $(S)$. The curve gives an estimated species richness for a standardized sampling effort:

$$
S=\alpha \log _{\mathrm{e}}\left(1+\frac{N}{\alpha}\right)
$$

This implicit function was solved iteratively using a 'Power Basic Program' written by R. Karlson. We used the mean number of individuals per transect (49) as our standardized sampling effort (Fisher et al. 1943). Assuming that diverse assemblages contain species with multiple morphologies and potential influences on nearby taxa, then coral richness can be interpreted as a proxy for the variety of mechanisms that potentially could facilitate other invertebrates. If this assertion is correct, we hypothesized that richness would be correlated positively with the diversity and abundance of invertebrates, and therefore with the strength of facilitation.

Coral cover was assessed by photographing each quadrat using color-slide film (Kodachrome 64) in a Nikonos V camera fitted with a $28 \mathrm{~mm}$ lens and Ikelite strobe (Model 100A) and mounted on a quadrapod. Percentage coral cover was quantified by placing a grid of 200 random dots over the projected images (at $20 \times 20 \mathrm{~cm}$ enlargement), and counting the number of dots falling on live coral. Reef rugosity has ecological importance by providing refuges and settlement areas for other taxa (Lewis \& Snelgrove 1990, Steele 1999), and in St. John was created by scleractinian corals (both alive and dead), other invertebrates (e.g. Millepora spp. and Porifera), and granite boulders. At the spatial scale of the quadrats used in this analysis, nearly all the structures contributing to rugosity were created by scleractinian corals (J. A. Idjadi unpubl.). Rugosity was assessed as 'Topographic complexity' (TC), and was calculated by conforming a chain (5 m long with $15 \mathrm{~mm}$ links) to the reef surface and dividing the conformed length by the linear distance to provide a dimensionless index (Rogers et al. 1982). For surveys completed in 1999, the sites were characterized by 4 TC measures that were recorded $1 \mathrm{~m}$ to each side, and at either end of the transect. For the surveys completed in 2000, the methodology was modified to reduce variance by recording $\mathrm{TC}$ in each of the 10 quadrats at all 12 sites.

Quantifying invertebrate community. The invertebrate community was characterized by the abundance and generic richness of non-scleractinian genera with the rationale that both metrics would be affected by putative coral facilitation. The abundance and richness of invertebrates was quantified by counting the benthic invertebrates within each quadrat that were visible without disturbing (e.g. turning over rocks) the substratum, and were $\geq 1 \mathrm{~cm}$ in diameter. Hereafter, these are referred to as 'conspicuous invertebrates'. Conspicuous invertebrates were identified to genus because of uncertain taxonomy or the difficulty of in situ identification, and individuals of colonial taxa were defined as autonomous areas of living tissue. For each site, the number of individuals of all genera was used to calculate the mean abundance (nos. $0.25 \mathrm{~m}^{-2}$ ) using quadrats as replicates, and Fisher's alpha predictions for species richness were made for a standardized sampling effort of 37 individuals (the mean number of 
individuals encountered per transect) after pooling quadrats within each site.

Statistical analyses. The overall community structure (percentage cover of coral and the abundance of conspicuous invertebrates) was compared among sites using 1-way ANOVA after transforming the data as necessary. The ANOVA assumptions of normality and homoscedasticity were tested through graphical analyses of the residuals.

All analyses were performed using Systat 8.0 software running on an IBM-compatible computer. Multiple regressions were used to test for relationships between the coral and invertebrate communities. This technique has advantages over correlation analyses because it permits a statistical analysis of the presence, strength and direction of the association between multiple, continuous, independent variables and a single, continuous, dependent variable (Sokal \& Rohlf 1995). Multiple regressions were completed using the 25 sites as statistical replicates, and 2 separate analyses were completed. First, the relationship between the abundance of conspicuous invertebrates (dependent variable) and percent coral cover, coral species diversity and topographic complexity (independent variables) was assessed. Second, the dependent variable was changed to the generic diversity of conspicuous invertebrates without changing the independent variables. The magnitude of the effect of each independent variable was evaluated using the standardized coefficients (SC). SCs represent the change (in standard deviations) in the dependent variable that would result from a 1 SD deviation change in the independent variable. Thus, the influence of each of the independent variables can be compared to other independent variables and the magnitude and direction of their effect can be evaluated.

For both multiple regressions, data were tested for normality using Kolmogorov-Smirnov tests, and logtransformed where appropriate to correct for skewness. In multiple-regression analyses, the independent variables can be influenced by each other (although they are not significantly related) as long as they have dissimilar effects on the dependent variables (Tabachnik \& Fiddel 1996). Arguably, this is the case with the present analysis, where the independent variables are interrelated because they are constructs of scleractinian corals, but they are likely to affect invertebrates in dissimilar ways. For example, coral cover probably influences invertebrates through the release of mucus and DOM, as well as the occupation of space that might otherwise be used for settlement. Coral diversity might mediate invertebrate diversity by creating a variety of morphological niches, and topographic complexity might relate to the broad availability of spatial refuges that mediate invertebrate density.

\section{RESULTS}

Qualitative analyses indicated that in 1999 and 2000 most of the 25 study sites were characterized by low coral cover $(\leq 10 \%$; the highest was $17 \%)$ and large amounts of macroalgae $(\approx 40 \%$ cover $)$ and crustose coralline algae $(\mathrm{C})$, algal turf $(\mathrm{T})$ and bare space $(\mathrm{B})$ combined $\left(\mathrm{CTB}_{;} \approx 40 \%\right.$ cover) (J. A. Idjadi unpubl.). These values for the percentage cover of the dominant benthic taxa are broadly similar to those characterizing nearby areas at 7 to $9 \mathrm{~m}$ depth (Edmunds 2002), although at least one area at $14 \mathrm{~m}$ depth in Great Lameshur Bay had $43 \%$ coral cover, 13\% macroalgal cover and 14\% CTB in 1998 (Edmunds 2002). Based on $0.25 \mathrm{~m}^{2}$ photoquadrats recorded on these nearby areas in 1999 ( $\mathrm{n}=104$ quadrats) and $2000(\mathrm{n}=108$ quadrats), the 2 study years did not differ significantly with regards to coral cover on the shallow reefs $(F=3.454, \mathrm{df}=1,210, \mathrm{p}=0.064)$, although they differed significantly in terms of cover of macroalgae and CTB $(F>13.407, \mathrm{df}=1,210, \mathrm{p}<0.001)$. As the present analysis tested for a relationship between coral traits and invertebrate traits using surveys from 2 consecutive summers, it is important that coral cover did not change between years in order to reduce the likelihood that temporal variation biased the outcome of our analyses. The temporal variation in cover of macroalgae and CTB was a result of enhanced macroalgal cover at the expense of CTB in 1999, with the reverse occurring in 2000. We do not know the extent to which the changes in macroalgal cover affected invertebrate populations, but the effect probably was small because macroalgae covered $\leq 30 \%$ of the reef in both years, and still covered $22 \%$ of the reef in 2000 .

Some study sites used in the present analysis consisted of a pavement of coral, rubble and sand $(\mathrm{TC}=1$, e.g. Sites 2 and 3 [site codes in Fig. 1]), while others contained boulders of living coral colonies (e.g. Sites 20 and 21) or granite ( 0.5 to $10 \mathrm{~m}$ in diameter as at Site 13); 3 sites $(23,24$ and 25) were dominated by granite cliffs that were relatively smooth and nearly vertical. In general, the highest coral cover and greatest diversity of corals and conspicuous invertebrates were at sites on the eastern margin of the study range (e.g. Sites 19, 20 and 21), notably in the lee of Cabritte Horn. Intermediate coral cover, coral diversity and diversity of conspicuous invertebrates were found at the tips of the headlands (e.g. Sites 1 and 23, 24 and $25)$, and the lowest values for these traits at sites within the bays (e.g. Sites 2, 3, 9 and 10). Overall, there was a high degree of variability in coral reef communitystructure among the sites (Fig. 1). When comparisons were made across the 25 sites, significant differences among sites were detected for coral cover $(F=3.200$, $\mathrm{df}=13,246, \mathrm{p}<0.001$ ), and the abundance of conspi- 
cuous invertebrates $(F=4.810, \mathrm{df}=13,246, \mathrm{p}<0.001)$. The among-site variation is also reflected in the range of values on the abscissas and ordinates of the scatterplots in Fig. 2, which display the relationships among coral traits and invertebrate traits (see below).

The surveys at 25 sites revealed 1404 scleractininian coral colonies that represented 28 species, 17 genera and 8 families; the majority comprised Montastraea annularis (25\%), Agaricia agaricites (13\%), and Porites astreoides $(13 \%)$, with most species occurring in $<20$ of the 250 quadrats surveyed. The surveys also revealed 2791 conspicuous invertebrates that represented 7 phyla, 9 classes and 72 genera; the majority belonged to the Demospongia (37\%), Anthozoa $(22 \%)$ and Polychaeta (18\%), and most (77\%) were suspension-feeders. Although some of the conspicuous invertebrates were found in most quadrats (e.g. Echinometra sp. was recorded in $80 \%$ of the quadrats), the modal density of most genera was zero (i.e. they were rare). In other words, there were a few genera represented by numerous individuals, but many genera that were represented by only a few individuals. An appendix containing the species lists and the relative abundance of each taxon is available on request from the first author.

The analyses of the relationships between coral traits and invertebrate traits provided incongruent results, with a significant association between corals traits and diversity of conspicuous invertebrates, but not between coral traits and the abundance of conspicuous invertebrates (Table 1). The proportion of the variance in the dependent variable that was accounted for by the independent variables was relatively large for the diversity of conspicuous invertebrates (55\%), but small for their abundance $(0.016 \%)$. In the significant relationship between coral traits and invertebrate diversity, topographic complexity (TC) had the greatest influence on invertebrate diversity. Coral diversity had a slight positive relationship with the diversity of conspicuous invertebrates ( $\mathrm{SC}=0.032$ ), TC was positively related with the diversity of conspicuous invertebrates, and coral cover was slightly negatively related to the diversity of conspicuous invertebrates. In summary, the SCs indicate that the diversity of conspicuous invertebrates is increased by greater coral-generated structure, and has little relationship to coral cover and coral diversity. Invertebrate abundance is unrelated to these coral-related traits.

\section{DISCUSSION}

The domination of coral reefs by scleractinian corals is likely to facilitate the diversity of other taxa-notably benthic invertebrates and demersel fishes - and
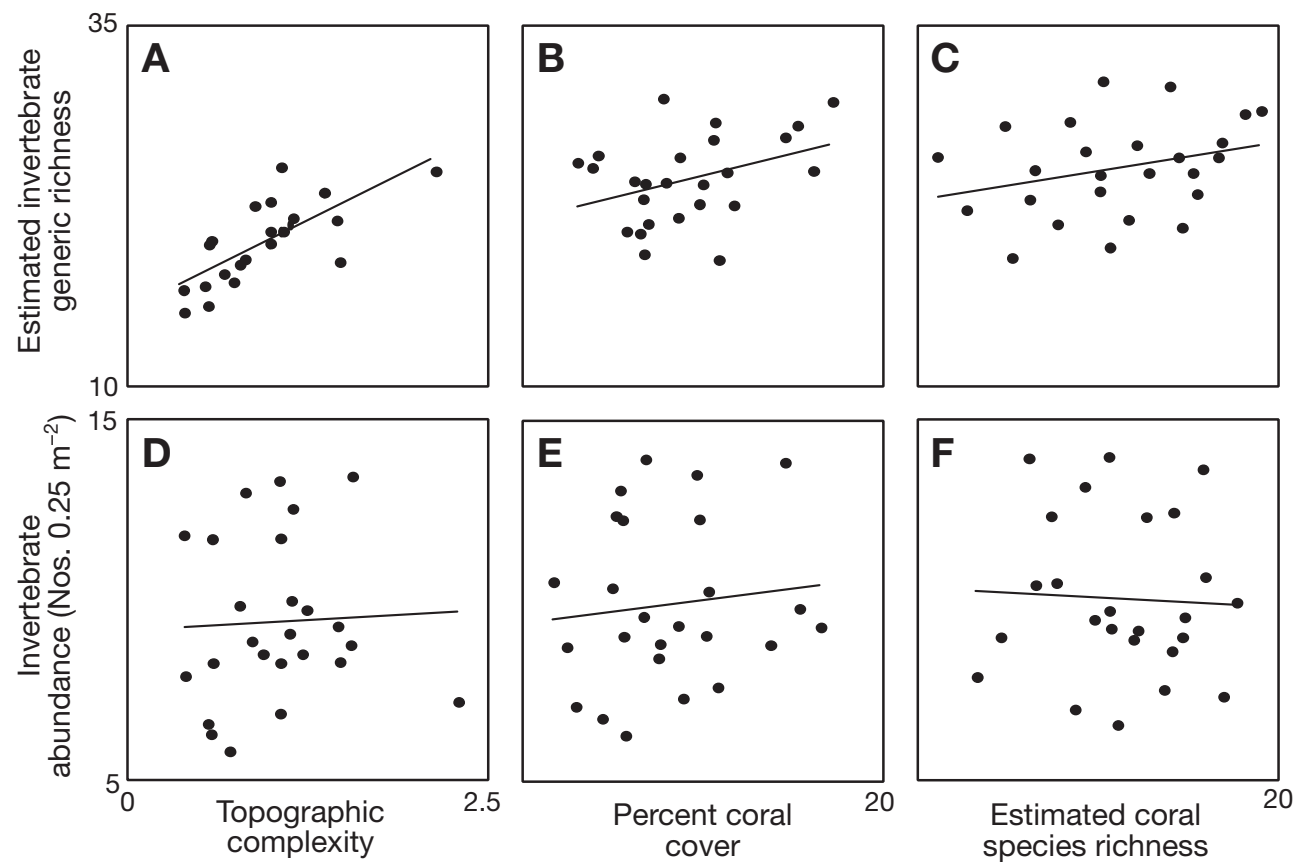

Fig. 2. Relationship between coral community traits and associated invertebrates. Coral community traits are (A,D) topographic complexity, $(\mathrm{B}, \mathrm{E})$ percent cover and $(\mathrm{C}, \mathrm{F})$ Fisher's alpha estimates of coral species richness. Invertebrate traits are (A-C) Fisher's alpha estimates of invertebrate generic richness and (D-F) abundance. Transects were used as replicates and quadrats are pooled ( $\mathrm{n}=25$ for each plot). Each row of graphs depicts variables that are components of each of 2 multiple regressions (i.e. A-C comprise a multiple regression, as do D-F). The first of these relationships was significant $(F=8.522, \mathrm{df}=3,21, \mathrm{p}=0.001)$. 
this has led to parallels being drawn between coral reefs and salt marshes, kelp forests and mussel beds that are model systems for illustrating the importance of facilitative interactions (Estes \& Palmisano 1974, Bertness \& Hacker 1994). Despite extensive de facto recognition of the importance of facilitation by reef corals (Jones et al. 1997, Bruno \& Bertness 2000), there is little quantitative evidence describing the scope and consequences of this facilitation. The present study is among the first to explicitly quantify the association between scleractinian corals and other reef invertebrates, and our results from shallow Caribbean reefs show that scleractinian traits are associated with the diversity of conspicuous invertebrates, but not their abundance. These results underscore the strong likelihood that the worldwide loss of reef corals (Hughes et al. 2003) is being accompanied by reductions in invertebrate diversity. Because the abundance of invertebrates is less affected by changes in coral traits, presumably because shifts in relative abundance of individual taxa compensate for species losses, declines in invertebrate diversity may avoid detection by human observers until severe. Based on the putative mechanistic basis of scleractinian facilitation (described below), methods to enhance invertebrate diversity on denuded coral reefs (i.e. reefrestoration efforts) will be most successful if they include the placement of structural components (e.g. coral transplants or artificial reefs) that mimic both the topographic and morphological complexity of the reef corals they are intended to replace.

Given the mensurative scope of the present study and the characteristics of the scleractinian communities that were quantified, the statistical association between coral traits and invertebrate traits are consistent with several non-exclusive hypotheses. Assuming that a hypothesis of random association can be rejected (based on the rigor obtained by sampling 25 sites, and on the detection of a pattern consistent with decades of qualitative observations: Bruno \& Bertness 2000), the remaining hypotheses fall into 2 camps. First, the association could reflect the independent yet systematic responses of scleractinians and conspicuous invertebrates to environmental conditions varying spatially among the study sites. Therefore, conditions favoring scleractinians also enhance the diversity of conspicuous invertebrates, and conditions that are detrimental to scleractinians also are harmful to conspicuous invertebrates. Depending on the scale of investigation and and the nature of the conditions involved, such relationships could be construed as evidence in support of the intermediate-disturbance hypothesis (Connell 1978). The study of Aronson \& Precht (1995) from the Belizean Barrier Reef provides a particularly interesting example of this conceptual approach because they used topographic complexity - as in the present analysis - as an integrated measure of disturbance and explored the relationship between TC and scleractinian diversity on the scale of reef spurs. For this location and the spatial scale investigated, Aronson \& Precht (1995) found that TC and scleractinian diversity were associated in a pattern consistent with the predictions of the intermediate-disturbance hypothesis. Although their study was restricted to scleractinians, it is not unreasonable to expect that the relationship between a proxy for disturbance (TC) and diversity would extend to other taxa, at least at the same spatial scale. However, in the case of the present analysis, we feel it is unlikely that the relationships between coral traits and invertebrate traits can be explained by a common response to environmental conditions, in part because disturbance regimes do not vary greatly among the sites investigated (P. J. Edmunds unpubl. data and pers. obs.), and in part because the factors affecting invertebrate diversity operate over regional scales (Cornell \& Karlson 2000) rather than the local scales (i.e. $<20 \mathrm{~km}$, sensu Mittelbach et al. 2001) exploited here $(2 \mathrm{~km})$. Thus, quadrat-scale diversity patterns are more likely to be influenced by the coral-generated habitat features occuring at the same spatial scale (Siemann 1998, Rypstra et al. 1999). The second group of hypotheses to explain our results focuses on the mechanisms by which scleractinians could facilitate 
conspicuous invertebrates, namely through the creation of morphologically diverse topographic niches and the mediation of their availability through coverage (or exposure) by living coral tissue.

The biological importance of topographic complexity (TC) in mediating the facilitative role of scleractinian corals is suggested by the explanatory power of this trait in the multiple regressions using invertebrate diversity as the dependent variable. In this context, the use of TC as a proxy for invertebrate refuges undoubtedly underestimates these resources by the extent to which the measurement chain cannot be conformed to all surfaces. This possibility applies both at the small scale of the quadrats/transects and at the scale of the study site, which sometimes included massive (i.e. $10 \mathrm{~m}$ in length) granite boulders. Not withstanding these limitations, our TC measurements in St. John reflect the structural framework of coral skeletons on a scale commensurate with the analysis of the other invertebrates. The use of coral skeletons for habitats by reef-dwelling organisms is well documented (Choi \& Ginsburg 1983, Steele 1999), with skeletal fragments and the undersurfaces and interstices of coral colonies creating what has been defined as coelobitic habitats (sensu Choi \& Ginsburg 1983). In such locations, the exclusion of predators and grazers enhances the abundance of other taxa (Choi \& Ginsburg 1983, Lewis \& Snelgrove 1990, Meesters et al. 1991, Steele 1999), for example, as shown by the 367 invertebrate species (mostly sponges) in coral rubble in at least 2 Caribbean locations (Meesters et al. 1991). The positive relationship between coral skeletons and the density and species richness of demersal fishes (Steele 1999) probably also represents the effect of predator exclusion. The association between coral traits (particularly TC) and invertebrate diversity, but not their abundance, suggests that the relationship is not simple, i.e. that it is dependent on the quantity of spatial refuges but is also influenced by the quality (structure and shape) of the refuges.

It is likely that sites with high coral diversity provide a greater variety of habitats and refuges for conspicuous invertebrates compared to sites with low coral diversity, based simply on the morphological diversity of the coral species. For example, the branching morphology of Acropora cervicornis provides a plethora of refuge opportunities for invertebrates, whereas fewer are provided by the short and stubby branches of Porites porites and P. furcata, and virtually none by massive colonies of Colpophyllia natans and Diploria strigosa. In the context of the present study - in which coral diversity and topographic complexity are positively related to the diversity of the invertebrates associated with the reef-it is interesting that the epifaunal community associated with Acropora spp. on the Great Barrier Reef is also strongly affected by coral morphology (Vytopil \& Willis 2001). In this case, the epifaunal community is more abundant and speciose on corals with tightly branched, as opposed to openbranched, corallum morphologies (Vytopil \& Willis 2001). Thus, the role of coral morphologies in creating habitat complexity and facilitating the occurrence of diverse invertebrate communities appears to be a generalizable property of reef corals, most notably in 2 distinct and separate biogeographic regions (i.e. the tropical Pacific [e.g. Vytopil \& Willis 2001] and the West Atlantic/Caribbean [Lewis \& Snelgrove 1990, Stachowicz \& Hay 1999, present study]).

Several studies have found that coral mucus (generated by living coral cover) contributes significantly to food resources on coral reefs (Benson \& Muscatine 1974, Richman et al. 1975, Wild et al. 2004). Although on larger spatial scales, coral cover and the resultant mucus production might be expected to benefit other reef-dwelling invertebrates by imparting this nutritional benefit, on small spatial scales living coral cover would preempt space from other sessile invertebrates. Thus, perhaps it is not surprising that we found an almost negligible negative relationship between coral cover and invertebrate diversity and no discernible relationship between coral cover and invertebrate abundance.

In the present study, the strongest relationship to emerge was between coral traits and invertebrate diversity, with meter-scale topographic complexity exhibiting the greatest explanatory power for the variation in invertebrate diversity. A testable hypothesis to explain this outcome is that on coral reefs with low percentage cover of coral (e.g. $<10 \%$ ), the relic skeletons (i.e. those left behind after the coral tissue dies) and the structural diversity they create are the most important factors determining the diversity and structure of the invertebrate communities. To test this hypothesis, studies similar to the present one will need to be extended to reefs with coral cover and diversity greater than currently available at St. John. However, support for this hypothesis is already available for Caribbean Acropora palmata populations that were severely affected by white-band disease in the 1980s (Aronson \& Precht 2001). In this case, the dead colonies continued to support a rich invertebrate community while they remained in growth position, but when this framework was damaged by hurricanes, the reef-associated taxa were severely depleted (Aronson \& Precht 2001). The potential duality of the relationship between corals and invertebrates (involving live coral cover or their relic skeletons) is important because it suggests that the mechanistic basis of this relationship will differ between reefs with high coral cover and those with low coral cover. If this is correct, then reef 
degradation may be accompanied by at least 2 crises for the invertebrate community, the first precipitated by the loss of coral cover, and the second by the loss of reef structure as coral skeletons erode through biotic and abiotic agents.

Aside from providing physical habitat, there may be indirect benefits of scleractinian skeletons. Chief among these is the role played by coral skeletons in mediating benthic boundary-layer dynamics and reefwide patterns of water flow (Hearn et al. 2001). As the roughness of the reef increases, it promotes turbulent flow (Shashar et al. 1996), which enhances the contact rate of planktonic prey with benthic suspensionfeeding organisms (Shashar et al. 1996), the delivery of pelagic larvae to benthic surfaces (Walters et al. 1997), and the flux rate of metabolically important metabolites as a result of a thinner diffusive boundary-layer (Hearn et al. 2001). All 3 effects would be expected to be potentially important mechanisms (Walters et al. 1997, Hearn et al. 2001) driving a positive relationship between topographic complexity and conspicuous invertebrates.

The present study supports the notion that scleractinian corals facilitate (sensu Bruno \& Bertness 2000) the presence of diverse invertebrate communities and, given the roles of their skeletons in providing settlement area, habitats, refugia and beneficial boundarylayer dynamics, function as autogenic ecosystem engineers (sensu Jones et al. 1997). Clearly, however, facilitation is not the only (or necessarily the most important) mechanism determining the types and density of invertebrates that live in close association with scleractinian corals. Indeed, based on the proportion of the variation in invertebrate diversity and abundance $(\leq 55 \%)$ explained by coral traits, the majority of the variance has yet to be explained. Presumably, this reflects the effects of random processes as well as other deterministic events such as competition and predation.

From the early days of ecology, there have been numerous examples illustrating the importance of habitat heterogeneity for species diversity (Tews et al. 2004), and here we show the potential for the heterogeneous habitats created by corals to promote the diversity of other invertebrates. Coral reefs are among the most diverse ecosystems known, so it is noteworthy that positive interactions among community members, rather than competition, may be among the significant mechanisms driving diversity in this system. In the present study, our power of inference was limited because the study was correlational and included only conspicuous invertebrates. While the study established the relationship between patterns of coral-mediated traits and invertebrate diversity, simple experiments could easily be set up to test our conclusions. For example, transplants of sessile invertebrates could be made to test the importance of living coral on the growth and survival of these organisms. Settlement plates could be placed in areas with high and low coral-generated habitat heterogeneity to test the importance of coral features on the recruitment of invertebrates, thereby gaining insight into the mechanisms by which corals facilitate the occurrence of other invertebrates. In short, the present study provides an important step in our understanding of the role of facilitation on coral reefs.

Acknowledgements. This project was supported with funding from the reef assessment program of the VI National Park, the Percy Sladen Memorial Fund, the Conservation and Research Foundation, the Research and Grants program of California State University Northridge, PADI project A.W.A.R.E. and, in part, by the National Science Foundation (DEB 0343570). We thank S. V. Vollmer, R. Habeeb, and V. Manfredi for field assistance, the staff of the Virgin Islands Environmental Resource Station for housing and on-site support, and S. Prosterman for ensuring access to SCUBA tanks and an aircompressor. We are deeply grateful to R. Karlson for his advice and programming work for the richness estimates. This work was submitted in partial fulfillment of the MS degree to J.A.I. at California State University, Northridge. Thanks to R. C. Carpenter, S. Dudgeon and R. Karlson for comments that improved an earlier draft of the manuscript. This paper is contribution number 135 of the CSUN marine biology program.

\section{LITERATURE CITED}

Aronson RB, Precht WF (1995) Landscape patterns of reef coral diversity: a test of the intermediate disturbance hypothesis. J Exp Mar Biol Ecol 192:1-14

Aronson RB, Precht WF (2001) White-band disease and the changing face of Caribbean coral reefs. Hydrobiologia 460:25-38

Atkinson MJ, Bilger RW (1992) Effects of water velocity on phosphate uptake in coral reef-flat communities. Limnol Oceanogr 37:273-279

Benson AA, Muscatine L (1974) Wax in coral mucus - energy transfer from corals to reef fishes. Limnol Oceanogr 19: 810-814

Bertness MD, Hacker SD (1994) Physical stress and positive associations among marsh plants. Am Nat 144:363-372

Bronstein JL (1994) Conditional outcomes in mutualistic interactions. Trends Ecol Evol 9:214-217

Bruno JF, Bertness MD (2000) Habitat modification and facilitation in benthic marine communities. In: Bertness MD, Hay ME, Gaines SD (eds) Marine community ecology. Sinauer, Sunderland, MA, p 201-218

Bruno JF, Stachowicz JJ, Bertness MD (2003) Inclusion of facilitation into ecological theory. Trends Ecol Evol 18:119-125

Callaway RM (1998) Are positive interactions species specific? Oikos 82:202-207

Choi DR, Ginsburg RN (1983) Distribution of coelobites (cavity dwellers) in coral rubble across the Florida reef tract. Coral Reefs 2:165-172

Clark S, Edwards AJ (1994) The use of artificial reef structures to rehabilitate reef flats degraded by coral mining in the Maldives. Bull Mar Sci 55:726-746 
Coffroth MA (1984) Ingestion and incorporation of coral mucus aggregates by a gorgonian soft coral. Mar Ecol Prog Ser 17:193-199

Connell JH (1961) Influence of interspecific competition and other factors on the distribution of the barnacle Chthamalus stellatus. Ecology 42:710-723

Connell JH (1973) Population ecology of reef-building corals. In: Jones OA, Endean R (eds) Biology and geology of coral reefs. Vol 2. Academic Press, New York, p 205-245

Connell JH (1978) Diversity in tropical rain forests and coral reefs. Science 199:1302-1310

Connell JH (1997) Disturbance and recovery of coral assemblages. Coral Reefs 16(Suppl):S101-S113

Cornell HV, Karlson RH (2000) Coral species richness: ecological versus biogeographical influences. Coral Reefs 19: $37-49$

Dayton PK (1971) Competition, disturbance, and community organization: the provision and subsequent utilization of space in a rocky intertidal community. Ecol Monogr 41: 351-389

Dulvy NK, Mitchell RE, Watson D (2002) Scale-dependent control of motile epifaunal community structure along a coral reef fishing gradient. J Exp Mar Biol Ecol 278:1-29

Edmunds PJ (2002) Long-term dynamics of coral reefs in St. John, US Virgin Islands. Coral Reefs 21:357-367

Edmunds PJ, Witman JD (1991) Effect of hurricane Hugo on the primary framework of a reef along the south shore of St. John, US Virgin Islands. Mar Ecol Prog Ser 78:201-204

Estes JA, Palmisano JF (1974) Sea otters: their role in structuring nearshore communities. Science 185:1058-1060

Fisher RA, Corbet AS, Williams CB (1943) The relation between the number of species and the number of individuals in a random sample of an animal population. J Anim Ecol 12:42-58

Gardner TA, Cote IM, Gill JA, Grant A, Watkinson AR (2003) Long-term region-wide declines in Caribbean corals. Science 301(5635):958-960

Glasby TM, Connell SD (2001) Orientation and position of substrata have large effects on epibiotic assemblages. Mar Ecol Prog Ser 214:127-135

Gleason HA (1926) The individualistic concept of the plant association. Bull Torrey Bot Club 53:7-26

Hearn CJ, Atkinson MJ, Falter JL (2001) A physical derivation of nutrient-uptake rates in coral reefs: effects of roughness and waves. Coral Reefs 20(4):347-356

Heyward AJ, Negri AP (1999) Natural inducers for coral larval metamorphosis. Coral Reefs 18:273-279

Hughes TP, Baird AH, Bellwood DR, Card M and 12 others (2003) Climate change, human impacts, and the resilience of coral reefs. Science 301:929-933

Jones CG, Lawton JH, Shachak M (1997) Positive and negative effects of organisms as physical ecosystem engineers. Ecology 78:1946-1957

Kayanne H, Suzuki A, Saito H (1995) Diurnal changes in the partial pressure of carbon dioxide in coral reef water. Science 269:214-216

LaJeunesse TC (2002) Diversity and community structure of symbiotic dinoflagellates from Caribbean coral reefs. Mar Biol 141:387-400

LaJeunesse TC, Loh WKW, VanWoesik R, Hoegh-Guldberg O, Schmidt GW, Fitt WK (2003) Low symbiont diversity in southern Great Barrier Reef corals, relative to those in the Caribbean. Limnol Oceanogr 48:2046-2054

Lesser MP, Weis VM, Patterson MR, Jokiel PL (1994) Effects of morphology and water motion of carbon delivery and productivity in the reef coral, Pocillopora damicornis (Linnaeus): diffusion barriers, inorganic carbon limi- tation, and biochemical plasticity. J Exp Mar Biol Ecol 178:153-179

Lewis JB, Snelgrove PVR (1990) Corallum morphology and composition of crustacean cryptofauna of the hermatypic coral Madracis mirabilis. Mar Biol 106:267-272

McClanahan TR, Sala E, Stickels PA (2003) Interaction between nutrients and herbivory in controlling algal communities and coral condition on Glover's Reef, Belize. Mar Ecol Prog Ser 261:135-147

McCook LJ (1999) Macroalgae, nutrients and phase shifts on coral reefs: scientific issues and management consequences for the Great Barrier Reef. Coral Reefs 18: 357-367

Meesters ER, Knijn P, Willemsen R, Pennartz G, Roebers Z, van Soest RWM (1991) Sub-rubble communities of Curaçao and Bonaire coral reefs. Coral Reefs 10:189-197

Meikle G, Richards G, Yellowlees D (1988) Structural investigations on the mucus from six species of coral. Mar Biol 99: 187-193

Mittelbach GG, Steiner CF, Scheiner SM, Gross KL and 5 others (2001) What is the observed relationship between species richness and productivity? Ecology 82:2381-2396

Moran PJ (1986) The Acanthaster phenomenon. Oceanogr Mar Biol Annu Rev 24:379-480

Morse DE, Morse ANC, Raimondi PT (1994) Morphogenbased chemical flypaper for Agaricia humilis coral larvae. Biol Bull (Woods Hole) 186:172-181

Muscatine L, Falkowski PG, Porter JW (1984) Fate of photosynthetic fixed carbon in light-adapted and shadeadapted colonies of the symbiotic coral Stylophora pistillata. Proc R Soc Lond B 222:181-202

Paine RT (1966) Food web complexity and species diversity. Am Nat 100:65-75

Real LA, Brown JH (1991) Foundations of ecology. Chapter 1. University of Chicago Press, Chicago, IL

Richman S, Loya Y, Slobodkin LB (1975) The rate of mucus production by corals and its assimilation by the coral reef copepod Acartia negligens. Limnol Oceanogr 20:918-924

Rogers CS (1993) Hurricanes and coral reefs - the intermediate disturbance hypothesis revisited. Coral Reefs 12: $127-137$

Rogers CS, Beets J (2001) Degradation of marine ecosystems and decline of fishery resources in marine protected areas in the Virgin Islands. Environ Conserv 28:312-322

Rogers CS, Suchanek T, Pecora F (1982) Effects of hurricanes David and Frederic (1979) on shallow Acropora palmata reef communities: St. Croix, US Virgin Islands. Bull Mar Sci 32:532-548

Rogers CS, Garrison V, Grober-Dunsmore R (1997) A fishy story about hurricanes and herbivory: seven years of research on a reef in St. John, US Virgin Islands. Proc 8th Int Coral Reef Symp 1:555-560

Rypstra AL, Carter PE, Balfour RA, Marshall SD (1999) Architectural features of agricultural habitats and their impact on the spider inhabitants. J Arachnol 27:371-377

Shashar NS, Kinane P, Jokiel L, Patterson MR (1996) Hydromechanical boundary layers over a coral reef. J Exp Mar Biol Ecol 199:17-28

Siemann E (1998) Experimental tests of effects of plant productivity and diversity on grassland arthropod diversity. Ecology 79:2057-2070

Sokal RR, Rohlf FJ (1995) Biometry. The principles and practices of statistics in biological research, 3rd edn. WH Freeman, New York

Stachowicz JJ, Hay ME (1999) Mutualism and coral persistence: the role of herbivore resistance to algal chemical defense. Ecology 80:2085-2101 
Steele MA (1999) Effects of shelter and predators on reef fishes. J Exp Mar Biol Ecol 233:65-79

Tabachnik BG, Fiddel LS (1996) Using multivariate statistics, 3rd edn. Harper Collins College Publishers, New York

Tews J, Brose U, Grimm V, Tielborger K, Wichmann MC, Schwager M, Jeltsch F (2004) Animal species diversity driven by habitat heterogeneity/diversity: the importance of keystone structures. J Biogeogr 31:79-92

Vytopil E, Willis BL (2001) Epifaunal community structure in Acropora spp. (Scleractinia) on the Great Barrier Reef:

Editorial responsibility: Kenneth Heck (Contributing Editor), Dauphin Island, Alabama, USA implications of coral morphology and habitat complexity. Coral Reefs 20:281-288

Walters LJ, Hadfield MG, DelCarmen KA (1997) The importance of larval choice and hydrodynamics in creating aggregations of Hydroides elegans (Polychaeta: Serpulidae). Invertebr Biol 116:102-114

Wild C, Huettel M, Klueter A, Kremb SG, Rasheed MYM, Jørgensen BB (2004) Coral mucus functions as an energy carrier and particle trap in the reef ecosystem. Nature 428: $66-70$

Submitted: March 7, 2005; Accepted: November 29, 2005 Proofs received from author(s): July 26, 2006 